\title{
Novel Lean Type 2 Diabetic Rat Model Using Gestational Low Protein Programming
}

\author{
Dr. Chellakkan S. BLESSON, PhD, Dr. Amy K. SCHUTT, MD, Ms. Meena P. \\ BALAKRISHNAN, MS, Dr. Robia G. PAUTLER, PhD, Dr. Steen E. PEDERSEN, PhD, Dr. \\ Poonam SARKAR, PhD, Dr. Daniel GONZALES, MS, Dr. Gang ZHU, PhD, Dr. Juan C. \\ MARINI, PhD, Dr. Shaji K. CHACKO, PhD, Uma YALLAMPALLI, MS, and Dr. Chandra \\ YALLAMPALLI, PhD
}

\begin{abstract}
Background-Type 2 diabetes in lean individuals is not well studied and up to $26 \%$ of diabetes occurs in these individuals. Although the cause is not well understood, it has been primarily attributed to nutritional issues during early development.
\end{abstract}

Objective-Our objective was to develop a lean type 2 diabetes model using gestational low protein programming.

Study Design-Pregnant rats were fed control (20\% protein) or isocaloric low protein (6\%) diet from gestational day 4 until delivery. Standard diet was given to dams after delivery and to pups after weaning. Glucose tolerance test was done at 2, 4 and 6 months of age. Magnetic resonance imaging of body fat for the females was done at 4 months. Rats were sacrificed at 4 months and 8 months of age and their peri-gonadal, peri-renal, inguinal and brown fat were weighed and expressed relative to their body weight. Euglycemic-hyperinsulinemic clamp was done around 6 months of age.

\begin{abstract}
Results-Male and female offspring exposed to a low protein diet during gestation developed glucose intolerance and insulin resistance. Further, glucose intolerance progressed with increasing age and occurred earlier and was more severe in females when compared to males. Euglycemic hyperinsulinemic clamp showed whole body insulin resistance in both sexes, with females demonstrating increased insulin resistance compared to males. Low protein females showed a 4.5fold increase in insulin resistance while males showed a 2.5 -fold increase when compared to their respective controls. Data from magnetic resonance imaging on female offspring showed no difference in the subcutaneous, inguinal and visceral fat content. We were able to validate this observation by sacrificing the rats at 4 and 8 months and measuring total body fat content. This
\end{abstract}

Corresponding Author: Chandra Yallampalli, PhD, Professor and Director, Basic Sciences Perinatology Research Laboratories, Department of Obstetrics and Gynecology, Baylor College of Medicine, 1102 Bates Avenue, Suite \#1850, Houston, Texas 77030, Office: 832-824 4188, Fax: 832-825 7946, cyallamp@bcm.edu.

Disclosure Statement: The authors report no conflict of interest

Paper presentation information: These findings will be presented in 36th Annual Meeting - The Pregnancy Meeting ${ }^{\mathrm{TM}}$ of the Society for Maternal-Fetal Medicine, February 1 - 6, 2016, Atlanta, GA. USA.

Publisher's Disclaimer: This is a PDF file of an unedited manuscript that has been accepted for publication. As a service to our customers we are providing this early version of the manuscript. The manuscript will undergo copyediting, typesetting, and review of the resulting proof before it is published in its final citable form. Please note that during the production process errors may be discovered which could affect the content, and all legal disclaimers that apply to the journal pertain. 
showed no differences in body fat content between control and LP offspring in both males and females. Additionally, diabetic rats had a similar body mass index to that of the controls.

Conclusion-LP gestational programming produces a progressively worsening type 2 diabetes model in rats with a lean phenotype without obesity.

\section{Keywords}

Gestational Programming; Lean diabetes; glucose intolerance; insulin resistance; Type 2 diabetes

\section{Introduction}

Diabetes has reached epidemic proportions with 1 in 9 affected in the U.S., with projected estimates as high as 1 in 3 by 2050 (CDC) $)^{1,2}$. Type 2 diabetes (T2D) has been historically attributed to lifestyle and genetics, however recent studies indicate that an adverse uterine environment is associated with the development of T2D later in life ${ }^{3}$. Although various aspects of T2D are well studied, the pathogenesis, progression and mechanisms of the developmental origins of T2D are poorly understood.

A recent study on minority American populations showed that $13 \%$ of diabetic patients are of normal weight ${ }^{4,5}$ with a fivefold higher incidence in people of Asian origin ${ }^{4}$. Studies from India ${ }^{5}$ and the Caribbean islands $\mathrm{s}^{6,7}$ also report the presence of a lean diabetic population, with $1.6-26 \%$ and $5 \%$ prevalence, respectively. This has been primarily attributed to possible in utero nutritional issues ${ }^{8}$. As obesity is not required for the development of $\mathrm{T} 2 \mathrm{D}^{5,9}, 10$, in utero nutritional issues could be a causative factor for developing insulin resistance (IR) and glucose intolerance that predispose to T2D. T2D in these lean individuals is not well understood.

Various genetic, diet and chemically induced diabetic rodent models are utilized to study $\mathrm{T} 2 \mathrm{D}^{11-13}$. However, these models are accompanied by obesity and do not accurately mimic the lean T2D phenotype. Therefore, there is a need for a lean diabetic animal model to investigate various aspects of lean phenotype and to study the possible mechanisms of origin of lean T2D. Previous work has demonstrated that a gestational low protein (LP) diet increases the susceptibility of offspring to the development of metabolic diseases during adulthood $^{14,15}$. Our objective was to characterize a gestational protein restricted rat model that results in IR and glucose intolerance in offspring during adulthood, but that is not accompanied by obesity.

\section{Materials and Methods}

\section{Animals}

Timed pregnant (Day 4) Wistar rats ( 200g) were procured from Harlan Laboratories and were housed in a temperature-controlled room $\left(\sim 23^{\circ} \mathrm{C}\right)$ with a $14: 10$-hour light/dark cycle with unlimited access to food and water. Pregnant rats were fed control (20\% protein, Harlan Teklad, WI) or isocaloric LP (6\%) diet from gestational day 4 until delivery. Normal diet was given to mothers after delivery and to pups after weaning until the end of the study. The number of pups in the control and LP litters were culled to 8 pups per mother (pups 
with weights at extremes were euthanized) to ensure equal nutrient access for all offspring. Body weights and length of pups were recorded on a regular basis to calculate body mass index (BMI). Glucose tolerance test (GTT) and euglycemic-hyperinsulinemic clamp were performed in females at diestrus phase to minimize the influence of estrogens. Rats were sacrificed at 4 and 8 months to collect gonadal, peri-renal and inguinal fat pads and their weights were recorded. All experimental procedures were performed with approval by the Institutional Animal Care and Use Committee of Baylor College of Medicine.

\section{Glucose tolerance test (GTT)}

GTT was performed on male and female offspring at 2, 4 and 6 months of age to identify the progression of glucose intolerance. Rats were fasted for 6 hours and were administered glucose ( $1 \mathrm{~g} / \mathrm{kg}$ body weight i.p.). Blood glucose levels were measured using ACCUCHEK $^{\circledR}$ Nano (Roche USA) at $0,15,30,60,120$, and 180 min via saphenous puncture. Blood samples were collected in heparin-coated tubes for measuring fasting plasma insulin levels.

\section{Insulin levels}

Plasma insulin levels were measured using a rat insulin ELISA kit (Mercodia), following the manufacturer's instruction as reported earlier ${ }^{16}$.

\section{Homeostatic Model Assessment (HOMA)}

HOMA- Insulin resistance (HOMA-IR) and HOMA-Insulin sensitivity (HOMA-IS) were calculated to assess insulin resistance and insulin sensitivity of control and LP rats using the following equations ${ }^{17}$.

HOMA $-\mathrm{IR}=($ Fasting Glucose $(\mathrm{mg} / \mathrm{dL}) \times$ Fasting Insulin $(\mathrm{mU} / \mathrm{I})) \div 405$ HOMA- IS $=10000 \div($ Fasting Glucose $(\mathrm{mg} / \mathrm{dL}) \times$ Fasting Insulin $(\mathrm{mU} / \mathrm{I}))$

\section{Magnetic resonance imaging (MRI)}

Magnetic resonance imaging (MRI) of body fat for females was done at 4 months of age. Rats were anesthetized, placed in the animal holder (Bruker BioSpin, Billerica, MA) and imaged using 9.4T, Bruker Avance BioSpec Spectrometer/AVIII with a $21 \mathrm{~cm}$ horizontal bore (Bruker, BioSpin, Billerica, MA) and a $72 \mathrm{~mm}$ resonator. To delineate the distribution of adipose tissue in the rats, a Dixon Fat Imaging sequence was used with a repetition time $(\mathrm{TR})=800 \mathrm{~ms}$; echo time $(\mathrm{TE})=12 \mathrm{~ms}$; slice thickness $=2 \mathrm{~mm}$; number of slices $=24$; field of view $=7 \mathrm{~cm}$ and $256 \times 256$ matrix. Saturation slabs were also incorporated. For consistency between animals, the first slice was aligned directly below the kidneys. After acquisition, in house Matlab code was utilized to separate the water and fat images, and the fat images were then quantified. Images $(256 \times 256 \times 24$ voxels, $70 \times 70 \times 48 \mathrm{~mm})$ that were scanned for fat were imported into an imaging program (ROIeditor; www.mristudio.org). All fat was segmented out by setting a threshold over background which was about $10 \%$ of the maximum signal. Visceral, inguinal, and subcutaneous fat was successively segmented out manually, slice by slice, by first inclosing all visceral fat and 
then segmenting between inguinal and subcutaneous fat. The volumes of separate fat were then generated by subtraction. Total fat volume was computed from the total number of voxels above the threshold in each type. We were constrained by the size of the bore in our MRI device, and therefore unable to scan the males at 4 months of age due to their larger size relative to females.

\section{Euglycemic-hyperinsulinemic clamp}

Euglycemic-hyperinsulinemic clamp was done at 6 and 7 months of age for females and males respectively. Rats were fasted for 6 hours, and were restrained in an appropriately sized restrainer (Kent Scientific Corporation, CT). Tail vein catheter was inserted using PE-10 tubing at the proximal end of the tail. The catheter was connected to a ' $\mathrm{Y}$ ' connector which was connected to syringes filled with $50 \%$ glucose solution and insulin (HumulinR ${ }^{\circledR}$, Eli Lilly and Company). The syringes were mounted onto a syringe pump (Harvard Apparatus, MA). Insulin was constantly infused at a rate of $4 \mathrm{mU} /\left(\mathrm{kg}^{*} \mathrm{~min}\right.$ ) (Flow rate of 200 and $150 \mu \mathrm{l} /$ hour for males and females respectively). Blood samples for measuring glucose were obtained every 10-15 min from the tail tip. Glucose infusion rates were adjusted by trial and error until a steady state of blood glucose concentration was reached. Three consecutive readings within a range of $\sim 1 \mathrm{mM}$ blood glucose concentrations were considered to have reached a steady state. Glucose levels were clamped between 5-6mM.

\section{Statistical Analyses}

Statistical analyses were performed using GraphPad Prism. Data is presented as scatter plot with mean or mean \pm SEM. Comparison between two groups was performed using unpaired student's $t$ test. Comparisons between multiple groups were done with two way ANOVA followed by Bonferroni test. Differences were considered significant when $\mathrm{p}<0.05$.

\section{Results}

\section{LP offspring exhibited catch-up growth but had similar body mass index (BMI)}

Gestational LP programed offspring were smaller at birth when compared to the controls. Male LP pups weighed $4.5 \pm 0.15 \mathrm{~g}$ and were smaller $(\mathrm{p}<0.0001, \mathrm{n}=12-33)$ when compared to the male control pups $(5.8 \pm 0.08 \mathrm{~g})$. Female control pups were $5.7 \pm 0.07 \mathrm{~g}$ whereas females LP pups were significantly smaller $(\mathrm{p}<0.0001, \mathrm{n}=10-31)$ and weighed $4.9 \pm 0.14 \mathrm{~g}$. However, both male and female offspring in LP group showed catch-up growth and their weights were similar to the control group by around three months (Fig. 1A and B). Interestingly, both controls and LP programmed offspring showed similar BMI throughout the study period ( $\mathrm{n}=12-20$ in males and $10-20$ in females; Fig. $1 \mathrm{C}$ and $\mathrm{D}$ ).

\section{LP offspring show progressively worsening glucose intolerance}

Glucose tolerance tests were performed on control and LP programmed offspring at 2, 4 and 6 months to identify the progression of glucose intolerance ( $n=5-6$ in each group). The blood glucose levels peaked at $30 \mathrm{~min}$ after bolus intraperitoneal glucose administration and returned to basal levels by $180 \mathrm{~min}$. Total glucose response is calculated as the $\Delta$ glycemia area under the curve (AUC) using the trapezoidal method as reported earlier ${ }^{16}$. In male offspring, the peak glucose levels at $30 \mathrm{~min}$ were lower in LP (LP $10.6 \pm 0.6 \mathrm{mmol} / \mathrm{l} \mathrm{vs}$. 
control $12.8 \pm 0.5 \mathrm{mmol} / \mathrm{l}, \mathrm{p}<0.05$ ) at 2 months (Fig. $2 \mathrm{~A}$ ), similar (LP $10.9 \pm 0.5 \mathrm{mmol} / \mathrm{l}$ vs. control $9.0 \pm 1.3 \mathrm{mmol} / \mathrm{l}$ ) at 4 months (Fig. $2 \mathrm{E}$ ) and significantly higher (LP $11.7 \pm 0.4$ $\mathrm{mmol} / \mathrm{l}$ vs. control $9.2 \pm 0.4 \mathrm{mmol} / \mathrm{l}$ ) at 6 months (Fig. 2I) when compared to their corresponding controls. The $\triangle$ AUC shows that male LP offspring at 2 months were significantly $(\mathrm{p}=0.0328)$ more glucose tolerant $(\Delta$ AUC Glycemia, $486.5 \pm 35, \mathrm{mmol} / \mathrm{L}$ *180 minutes) when compared to their controls ( $\triangle$ AUC Glycemia, $690.6 \pm 71, \mathrm{mmol} / \mathrm{L}$ *180 minutes) (Fig. 2B). However by 4 months these LP males were more glucose intolerant ( $\mathrm{p}=0.0441$, Glycemia, $462.7 \pm 24, \mathrm{mmol} / \mathrm{L} * 180$ minutes) than controls $(\Delta$ AUC Glycemia, $312.2 \pm 54 \mathrm{mmol} / \mathrm{L} * 180$ minutes) (Fig. $2 \mathrm{~F}$ ), and this glucose intolerance further worsened at 6 months $(\mathrm{p}=0.0056 ; \Delta$ AUC Glycemia, $571.3 \pm 55 \mathrm{mmol} / \mathrm{L} * 180$ minutes in $\mathrm{LP}$ and $309.1 \pm 26 \mathrm{mmol} / \mathrm{L} * 180$ minutes in controls) (Fig. 2J). In females, peak glucose levels at $30 \mathrm{~min}$ after bolus administration were significantly higher in LP at 2 months (LP $12.3 \pm 0.8 \mathrm{mmol} / \mathrm{l}$ vs. control $10.3 \pm 0.8 \mathrm{mmol} / \mathrm{l}, \mathrm{p}<0.05 ;$ Fig. $2 \mathrm{C}$ ), 4 months (LP $10.9 \pm 1.4$ $\mathrm{mmol} / \mathrm{l}$ vs. control $8.1 \pm 0.3 \mathrm{mmol} / \mathrm{l}$; p $<0.05$; Fig. $2 \mathrm{G}$ ) and at 6 months (LP $10.2 \pm 0.6$ $\mathrm{mmol} / \mathrm{l}$ vs. control $7.5 \pm 0.3 \mathrm{mmol} / \mathrm{l}$; $\mathrm{p}<0.001$; Fig. $2 \mathrm{~K}$ ) when compared to their corresponding controls. However, $\triangle \mathrm{AUC}$ Glycemia values showed no differences in their glucose tolerance at 2 months ( $\mathrm{p}=0.7792,256.1 \pm 17.96, \mathrm{mmol} / \mathrm{L} * 180$ minutes in LP and $248.9 \pm 16 \mathrm{mmol} / \mathrm{L} * 180$ minutes in controls) (Fig. 2D), but showed glucose intolerance by 4 months ( $\mathrm{p}=0.0408 ; \Delta$ AUC Glycemia, $543.0 \pm 105 \mathrm{mmol} / \mathrm{L} * 180$ minutes in LP and $243.7 \pm 48 \mathrm{mmol} / \mathrm{L} * 180$ minutes in controls) (Fig. $2 \mathrm{H}$ ) and this condition was significantly worsened by 6 months ( $\mathrm{p}=0.0174 ; \Delta$ AUC Glycemia, $624.4 \pm 83 \mathrm{mmol} / \mathrm{L} * 180$ minutes in $\mathrm{LP}$ and $332.7 \pm 53 \mathrm{mmol} / \mathrm{L} * 180$ minutes in controls) (Fig. 2L). LP programmed females appear to have an earlier onset and faster progression of glucose intolerance when compared to the males.

\section{Fasting insulin concentrations did not show any difference between LP and control offspring}

Fasting insulin concentrations in plasma were measured in LP and control offspring in both sexes at 4 and 6 months. Insulin levels did not differ at 4 months (control, $479 \pm 95 \mathrm{pmol} / \mathrm{l}$; LP, $415 \pm 65 \mathrm{pmol} / \mathrm{l}$ ) or 6 months (control, $468 \pm 99 \mathrm{pmol} / \mathrm{l}$; LP, $552 \pm 56 \mathrm{pmol} / \mathrm{l}$ ) in males. Fasting insulin levels in females also did not differ between controls and LP at 4 months (control, $187 \pm 35 \mathrm{pmol} / \mathrm{l} ; \mathrm{LP}, 163 \pm 18 \mathrm{pmol} / \mathrm{l}$ ) and 6 months (control, $393 \pm 55 \mathrm{pmol} / \mathrm{l}$; LP, $383 \pm 35 \mathrm{pmol} / \mathrm{l})$. However, insulin levels in the female offspring were increased in both controls and LP at 6 months when compared to 4 months ( $\mathrm{p}<0.0001)$.

\section{HOMA}

HOMA IR and IS values for both males (Fig. 3A and B) and females (Fig. 3C and D) were similar between the control and LP offspring at 4 and 6 months of age $(n=5-7$ in each group). Interestingly, 6 months old females of both control and LP groups showed more insulin resistance $(\mathrm{p}<0.0001)$ and less insulin sensitivity $(\mathrm{p}<0.0001)$ when compared to 4 month old females indicating females show a dramatic increase in insulin resistance with age. 


\section{LP offspring were insulin resistant in euglycemic hyperinsulinemic clamp}

Euglycemic hyperinsulinemic clamp is the gold standard for measuring insulin resistance. Glucose concentrations during the clamp were maintained between $4.9 \pm 0.2$ and $5.9 \pm 0.4$ $\mathrm{mmol} / \mathrm{L}$ during the steady state (Fig. $4 \mathrm{~A}$ and C). The glucose infusion rate was nearly 2.5 fold lower in LP males when compared to their controls $(9.1 \mu \mathrm{mol} /(\mathrm{kg} * \mathrm{~min})$ in LP vs. 23.4 $\mu \mathrm{mol} /(\mathrm{kg} * \mathrm{~min})$ in control; $\mathrm{P}<0.01, \mathrm{n}=5$, Fig. 4B). In LP females, the glucose infusion rate was 4.5 fold lower than their controls $(5.4 \mu \mathrm{mol} /(\mathrm{kg} * \mathrm{~min})$ in LP vs. $24.4 \mu \mathrm{mol} /(\mathrm{kg} * \mathrm{~min})$ in control; $\mathrm{P}<0.0001, \mathrm{n}=5-6$ Fig. 4D). Thus, our data shows that both male and female LP offspring have significantly greater insulin resistance when compared to their respective controls (Fig. 4A-D).

\section{MRI shows no change in the fat distribution between LP and control female offspring}

MRI was performed to identify if there were differences in the fat content and distribution between control and LP offspring $(n=5)$. Three dimensional MRI analyses showed no overall differences between controls and LP offspring and no significant changes in subcutaneous, visceral and inguinal fat distributions (Fig. 5). Representative video images of the MRI scan and three dimensional analyses are shown in supplementary video files 1-3.

\section{Fat depot weights showed no differences}

LP programmed and control rats from both sexes were sacrificed at 4 and 8 months of age and their fat depots (Peri-gonadal, peri-renal, inguinal and brown adipose tissue) were weighed ( $\mathrm{n}=12$ in males and $\mathrm{n}=10-12$ in females). No differences were observed in any of the fat depot between control and LP offspring in both males and females (data not shown). Total fat depot weights were similar among control and LP offspring at 4 and 8 months in both sexes (Fig. 6A and C) but they showed a significant ( $p<0.0001$ in males and $p<0.001$ in females) increase in the fat depot weights at 8 months when compared to 4 months. Normalization of the fat depot weights with their respective body weights also showed no differences in the \% fat contents (Fig. 6B and D) between controls and LP. This data indicates that LP offspring of both sexes were not obese and had adipose deposition comparable to their respective controls.

\section{Comment}

Diabetes is a metabolic disease caused by defects in insulin secretion, insulin action, or a combination of both resulting in hyperglycemia ${ }^{18}$. T2D is often associated with obesity and most research investigating T2D is performed using obese animal models. However, various clinical observations have shown the presence of T2D in lean or normal BMI individuals ${ }^{9,19-24}$. This atypical diabetic phenotype does not fit into the traditional classification of diabetes and is known by various names such as Jamaica type diabetes, metabolically obese normal weight diabetes, malnutrition related diabetes mellitus, phasic insulin dependent diabetes, tropical diabetes, mixed onset type diabetes, J type diabetes, $\mathrm{Z}$ type diabetes, $\mathrm{M}$ type or type 3 diabetes and ketosis resistant growth onset type diabetes $^{6,7,9,25-29}$. Although the existence of lean diabetes has been observed for decades, the etiology and pathophysiology of disease in this lean population is poorly understood. 
One of the common factors that connects various types of atypical lean diabetic phenotypes is the role of early nutrition ${ }^{14}$. Recent studies show that an adverse in utero environment is often associated with the development of T2D in offspring ${ }^{3}$. A gestational LP diet programs offspring to become susceptible to the development of metabolic diseases during adulthood $^{14,15}$. It is important to develop a rodent model that reflects such an adverse gestational environment with fetal nutritional deficiency to investigate the etiology and mechanisms underlying lean T2D. Published literature describing the lean T2D phenotype is often reported in developing nations among people with poor socio-economic status, strongly suggesting the possibility of developmental programming during early development ${ }^{7}, 14$.

We have shown for the first time that gestational LP programming produces a progressively worsening model of T2D in rats that is characterized by a lean phenotype and is without altered adipose tissue amount and distribution compared to controls. Our model shows that both males and females develop glucose intolerance and IR without obesity. Our earlier studies in this model show that males and females have distinct mechanisms leading to glucose intolerance and $\mathrm{IR}^{30}$. Our recent study in gastrocnemius muscles shows that male LP offspring are glucose intolerant and IR with increased basal expression and activation of insulin receptor along with compromised Glut4 membrane transport due to defective phosphorylations of IRS-1 and AS160 ${ }^{16}$. Defective Glut4 localization in the gastrocnemius muscles has also been reported in lean T2D patients ${ }^{31}$.

LP programmed females are glucose intolerant with intact Glut4 translocation mechanism. However, they have impaired phosphorylations in GSK3 pathway indicating sex differences in the mechanisms underlying the disease ${ }^{30}$. Fasting insulin levels did not show any changes and consequently HOMA-IR and IS also did not show any changes between the controls and LP programmed offspring. However, GTT and euglycemic hyperinsulinemic clamp showed glucose intolerance and IR in both sexes with females displaying a more aggressive phenotype when compared to males. Clinical studies have shown the presence of lean diabetes in both males and females ${ }^{5,32}$ with around twice the rate of incidence in females in one cohort ${ }^{32}$. However, large scale multi-centric clinical studies need to be undertaken to validate these findings.

The only other reported lean T2D model is called Goto-Kakizaki rats ${ }^{33,34}$. This model was developed by the repetitive breeding of Wistar rats with the poorest glucose tolerance ${ }^{33,}, 35$ and is characterized by glucose intolerance and flawed glucose-induced insulin secretion with defective glucose metabolism ${ }^{34}$. Although this model develops T2D, it is a reflection of the genetic makeup of the rats ${ }^{34}$ rather than developmental programming. Various existing obese rodent T2D models have contributed greatly to our understanding of the disease, however, they are inadequate to study the lean and pre-obese phenotypes associated with T2D.

We have characterized a novel lean T2D rat model which reflects various aspects of lean T2D. Lean T2D is poorly understood partly due the absence of a suitable animal model. This animal model opens up new vistas for investigators to study lean T2D and the role of nutrition during early development and its metabolic implications in later life. We believe 
that our unique lean gestational LP programming T2D model will be a useful tool to further understand the etiology, progression and severity of lean T2D and to investigate the underlying mechanisms, which may help us to devise appropriate treatment strategies.

\section{Supplementary Material}

Refer to Web version on PubMed Central for supplementary material.

\section{Acknowledgments}

Grant Support: This work was supported by National Institutes of Health Grants for C.Y. (HL102866 and HL58144)

The authors gratefully acknowledge the technical support by Ms. Inka Cajo Didelija, Children's Nutritional Research Center.

\section{References}

1. Number of Americans with Diabetes Projected to Double or Triple by 2050 Older, more diverse population and longer lifespans contribute to increase. Center for Disease Control and Prevention; 2010.

2. Prevention efforts crucial to combat serious health risks. Center for Disease Control and Prevention; 2014. More than 29 million Americans have diabetes; 1 in 4 doesn't know.

3. Duque-Guimaraes DE, Ozanne SE. Nutritional programming of insulin resistance: causes and consequences. Trends Endocrinol Metab. 2013; 24:525-35. [PubMed: 23791137]

4. Coleman NJ, Miernik J, Philipson L, Fogelfeld L. Lean versus obese diabetes mellitus patients in the United States minority population. J Diabetes Complications. 2014; 28:500-5. [PubMed: 24581791]

5. Barma PD, Ranabir S, Prasad L, Singh TP. Clinical and biochemical profile of lean type 2 diabetes mellitus. Indian J Endocrinol Metab. 2011; 15:S40-3. [PubMed: 21847453]

6. Hugh-Jones P. Diabetes in Jamaica. Lancet. 1955; 269:891-7. [PubMed: 13264638]

7. Report of a WHO Study Group. Diabetes mellitus. World Health Organ Tech Rep Ser. 1985; 727:1113. [PubMed: 3934850]

8. Yajnik CS. Early life origins of insulin resistance and type 2 diabetes in India and other Asian countries. J Nutr. 2004; 134:205-10. [PubMed: 14704320]

9. George AM, Jacob AG, Fogelfeld L. Lean diabetes mellitus: An emerging entity in the era of obesity. World J Diabetes. 2015; 6:613-20. [PubMed: 25987958]

10. Perry JR, Voight BF, Yengo L, et al. Stratifying type 2 diabetes cases by BMI identifies genetic risk variants in LAMA1 and enrichment for risk variants in lean compared to obese cases. PLoS Genet. 2012; 8:e1002741. [PubMed: 22693455]

11. Wang YW, Sun GD, Sun J, et al. Spontaneous type 2 diabetic rodent models. J Diabetes Res. 2013; 2013:401723. [PubMed: 23671868]

12. Islam MS, Loots du T. Experimental rodent models of type 2 diabetes: a review. Methods Find Exp Clin Pharmacol. 2009; 31:249-61. [PubMed: 19557203]

13. Islam MS, Wilson RD. Experimentally induced rodent models of type 2 diabetes. Methods Mol Biol. 2012; 933:161-74. [PubMed: 22893406]

14. Stocker CJ, Arch JR, Cawthorne MA. Fetal origins of insulin resistance and obesity. Proc Nutr Soc. 2005; 64:143-51. [PubMed: 15960859]

15. Barker DJ. The origins of the developmental origins theory. J Intern Med. 2007; 261:412-7. [PubMed: 17444880]

16. Blesson CS, Sathishkumar K, Chinnathambi V, Yallampalli C. Gestational protein restriction impairs insulin-regulated glucose transport mechanisms in gastrocnemius muscles of adult male offspring. Endocrinology. 2014; 155:3036-46. [PubMed: 24797633] 
17. Aref AB, Ahmed OM, Ali LA, Semmler M. Maternal rat diabetes mellitus deleteriously affects insulin sensitivity and Beta-cell function in the offspring. J Diabetes Res. 2013; 2013:429154. [PubMed: 23998129]

18. American Diabetes A. Diagnosis and classification of diabetes mellitus. Diabetes Care. 2010; 33(Suppl 1):S62-9. [PubMed: 20042775]

19. Sattar N, Gill JM. Type 2 diabetes in migrant south Asians: mechanisms, mitigation, and management. Lancet Diabetes Endocrinol. 2015

20. Mohan V, Vijayaprabha R, Rema M, et al. Clinical profile of lean NIDDM in South India. Diabetes Res Clin Pract. 1997; 38:101-8. [PubMed: 9483373]

21. Sutjahjo A, Taniguchi H, Hendromartono, Tjokroprawiro A, Baba S. High frequency of autonomic as well as peripheral neuropathy in patients with malnutrition-related diabetes mellitus. Diabetes Res Clin Pract. 1988; 5:197-200. [PubMed: 3219990]

22. Abu-Bakare A, Taylor R, Gill GV, Alberti KG. Tropical or malnutrition-related diabetes: a real syndrome? Lancet. 1986; 1:1135-8. [PubMed: 2871387]

23. Wajngot A, Roovete A, Vranic M, Luft R, Efendic S. Insulin resistance and decreased insulin response to glucose in lean type 2 diabetics. Proc Natl Acad Sci U S A. 1982; 79:4432-6. [PubMed: 6750603]

24. Sayeed MA, Azad Khan AK, Mahtab H, et al. Leptin is reduced in lean subjects with type 2 diabetes in bangladesh. Diabetes Care. 2003; 26:547. [PubMed: 12547904]

25. Ruderman NB, Schneider SH, Berchtold P. The "metabolically-obese," normal-weight individual. Am J Clin Nutr. 1981; 34:1617-21. [PubMed: 7270486]

26. Balasubramanyam, A.; Yajnik, CS.; Tandon, N. Non-Traditional Forms of Diabetes Worldwide: Implications for Translational Investigation. In: Robertson, RP., editor. Translational Endocrinology \& Metabolism: Type 2 Diabetes Update. Vol. 2. The Endocrine Society; 2011.

27. Morrison EY, Ragoobirsingh D, Thompson H, et al. Phasic insulin dependent diabetes mellitus: manifestations and cellular mechanisms. J Clin Endocrinol Metab. 1995; 80:1996-2001. [PubMed: 7608247]

28. Cuisinier-Raynal JC, Ducorps M, Grandpierre G. Tropical diabetes mellitus, a new nutritional indicator? Med Trop (Mars). 1985; 45:179-84. [PubMed: 3927107]

29. Hoet JJ, Tripathy BB. Report of the International Workshop on types of Diabetes Peculiar to the Tropics. Diabetes Care. 1996; 19:1014. [PubMed: 8875102]

30. Blesson, CS.; Chinnathambi, V.; Sathishkumar, K.; Yallampalli, C. Reprod Sci. Vol. 22. SAGE PUBLICATIONS INC; 2455 TELLER RD, THOUSAND OAKS, CA 91320 USA: 2015. Gestational Protein Restriction Causes Hyperglycemia By Affecting IRS-1 Tyrosine Phosphorylation and the Dysregulation of Akt-GSK3 Signaling in Adult Female Offspring.

31. Vogt B, Muhlbacher C, Carrascosa J, et al. Subcellular distribution of GLUT 4 in the skeletal muscle of lean type 2 (non-insulin-dependent) diabetic patients in the basal state. Diabetologia. 1992; 35:456-63. [PubMed: 1325931]

32. Chaudhary P, Laloo D, Salam R. Prevalence of lean type 2 diabetes mellitus in recently diagnosed type 2 diabetes mellitus patients. Indian J Endocrinol Metab. 2013; 17:S316-7. [PubMed: 24251199]

33. Goto Y, Kakizaki M, Masaki N. Production of spontaneous diabetic rats by repetition of selective breeding. Tohoku J Exp Med. 1976; 119:85-90. [PubMed: 951706]

34. Ostenson CG, Efendic S. Islet gene expression and function in type 2 diabetes; studies in the GotoKakizaki rat and humans. Diabetes Obes Metab. 2007; 9(Suppl 2):180-6. [PubMed: 17919192]

35. King AJ. The use of animal models in diabetes research. Br J Pharmacol. 2012; 166:877-94. [PubMed: 22352879] 
A

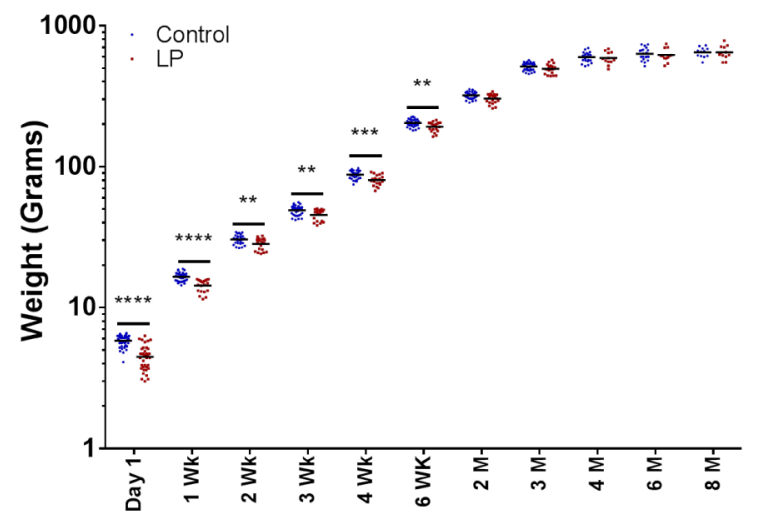

C

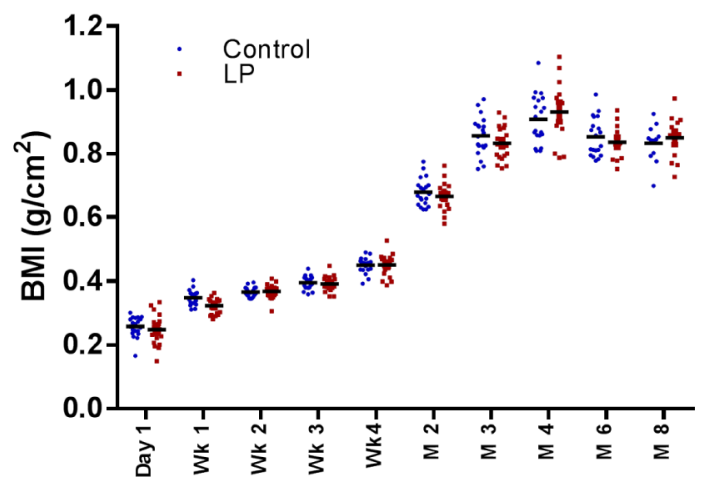

B
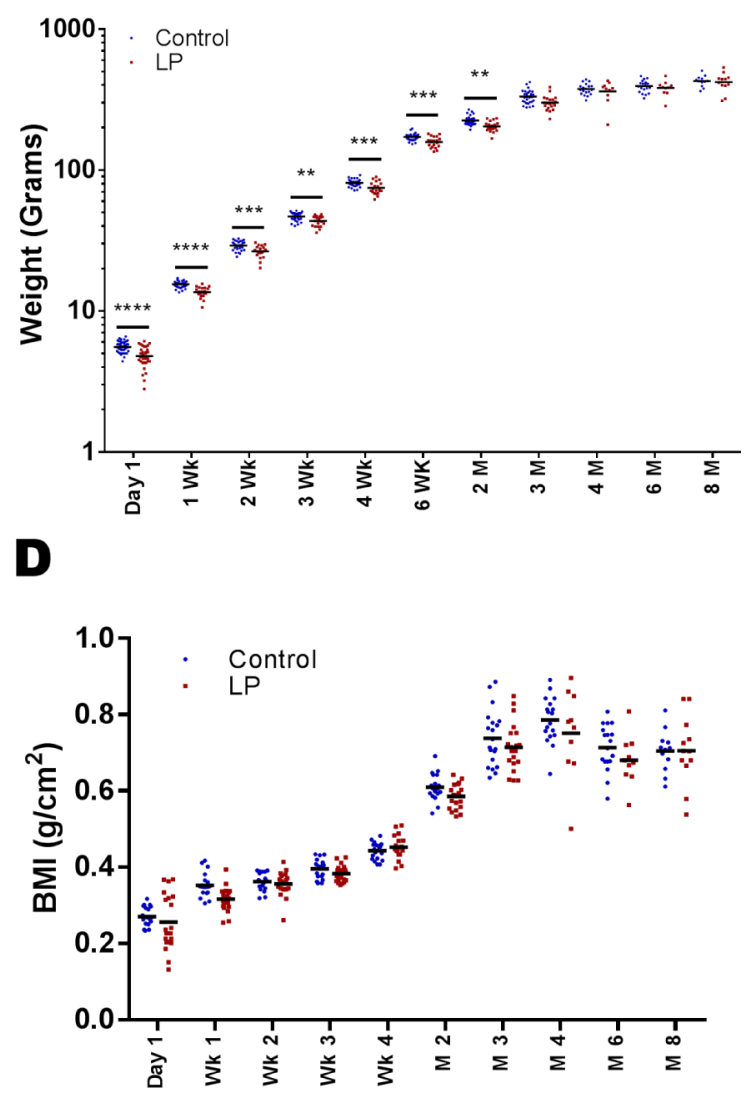

Figure 1.

Offspring weight and their BMI.

Figures showing the body weights of control and LP programmed male (A) and female (B) offspring and their respective body mass index (BMI) (C and D) from birth to 8 months of age. $*=\mathrm{p}<0.05, * *=\mathrm{p}<0.01, * * * \mathrm{p}<0.001$ and $* * * *=\mathrm{p}<0.0001(\mathrm{n}=12-33$ in males and 12-31 in females for weights and $\mathrm{n}=12-20$ in males and 10-20 in females for BMI) 
Males

A

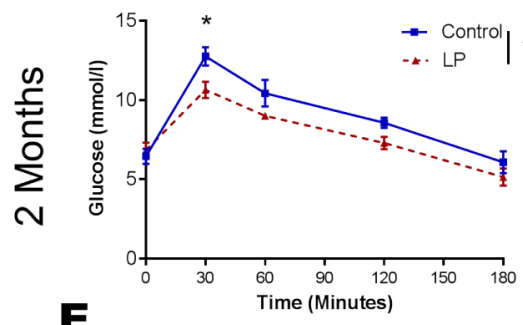

$\mathbf{E}$
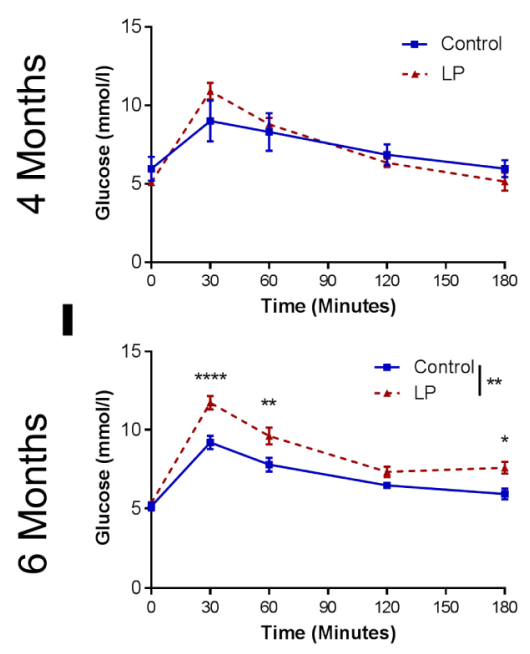

B

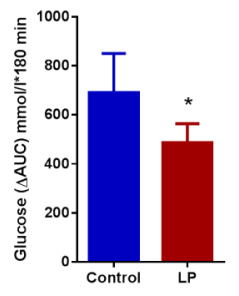

$\mathbf{F}$
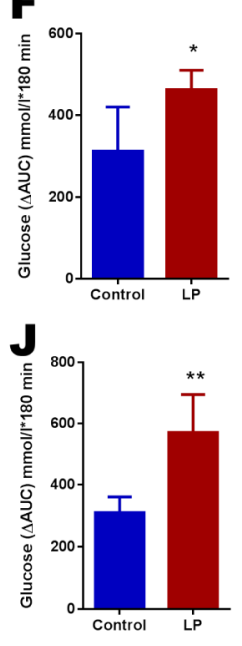

Females
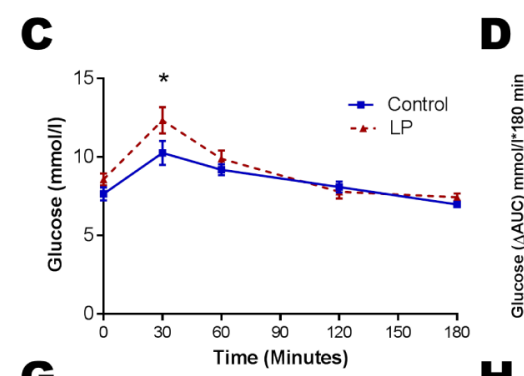

$\mathbf{G}$

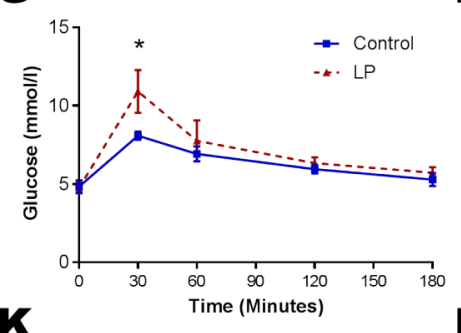

$\mathbf{H}$
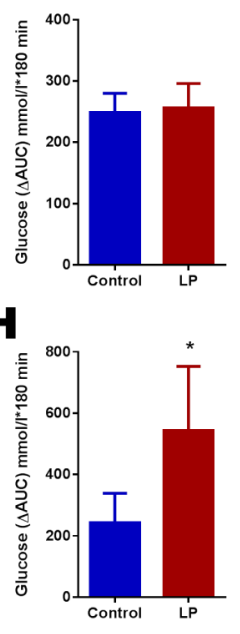

$\mathbf{K}$

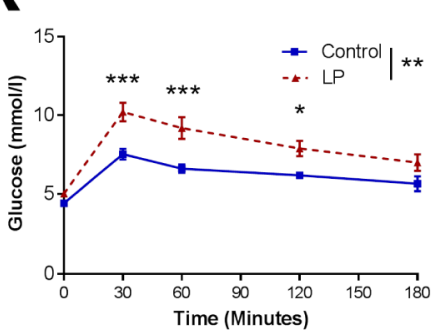

$\mathbf{L}$

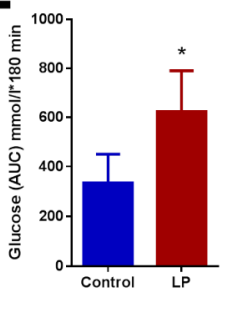

Figure 2.

Glucose tolerance of males and females at 2, 4 and 6 months.

Figures showing data from GTT (A, C, E, G, I and K) along with its corresponding $\Delta$ area under the curve (AUC) of male (B, F and J) and female LP (D, H and L) offspring at 2, 4 and 6 months. ${ }^{*} \mathrm{p}<0.05, * * \mathrm{p}<0.01,{ }^{*} * \mathrm{p} \mathrm{p}<0.001$ and $* * * * \mathrm{p}<0.0001(\mathrm{n}=5-6)$. 


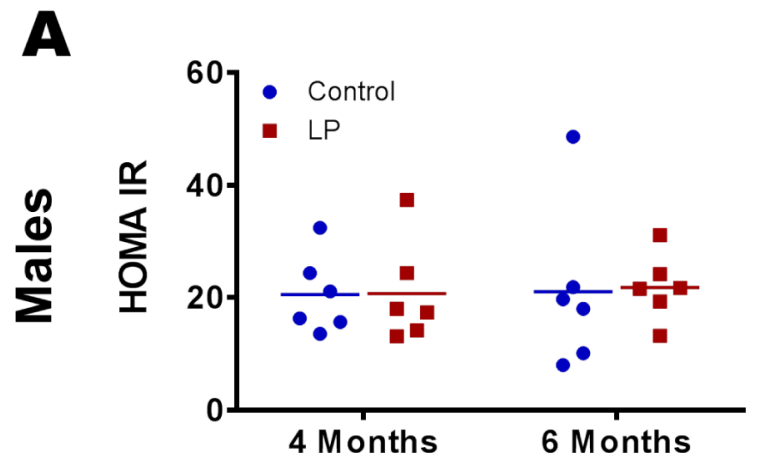

C

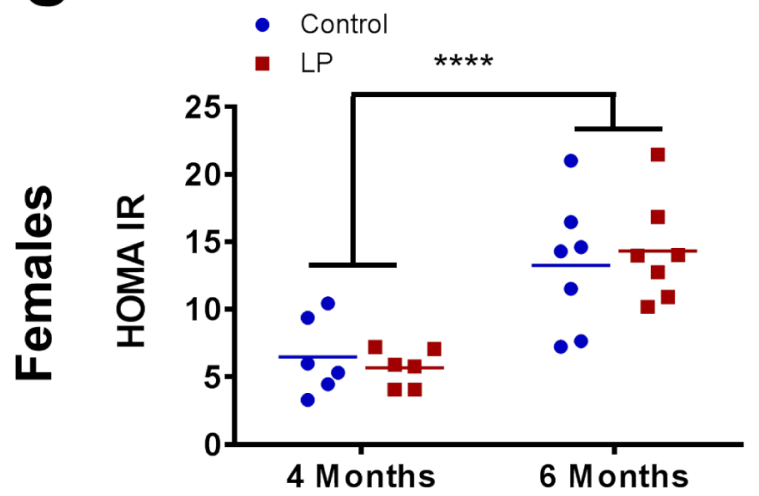

B

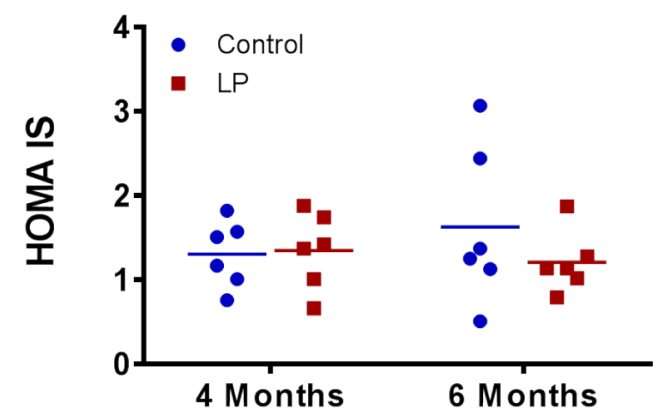

D

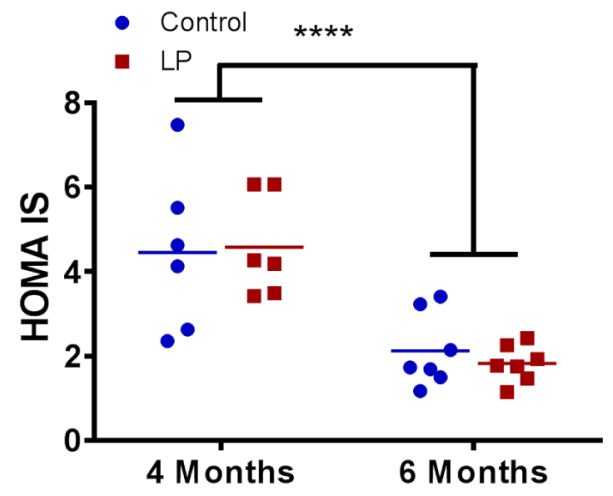

Figure 3.

HOMA insulin resistance and insulin sensitivity.

Figure showing the HOMA-IR and HOMA-IS of male (A and B) and female (C and D) offspring at 4 and 6 months of age. $* * * * p<0.0001,(n=5-7)$. 
A

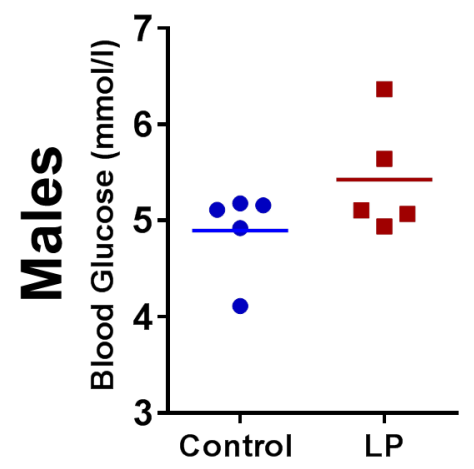

C

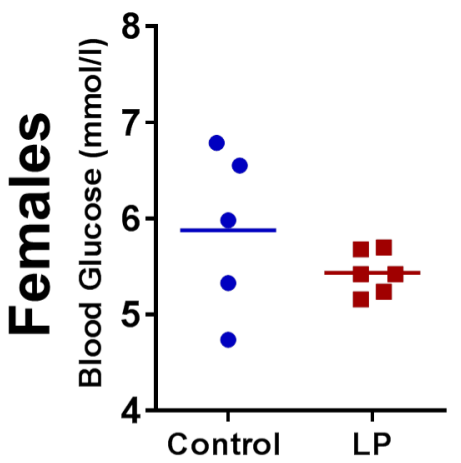

B

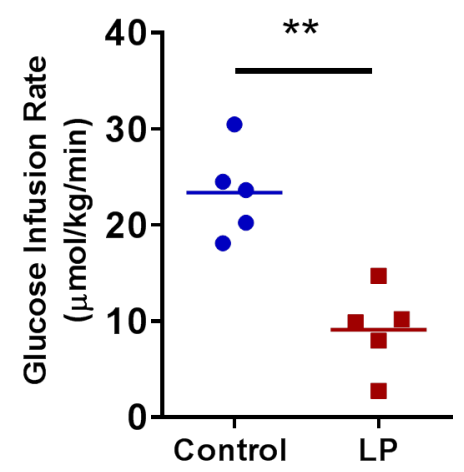

D

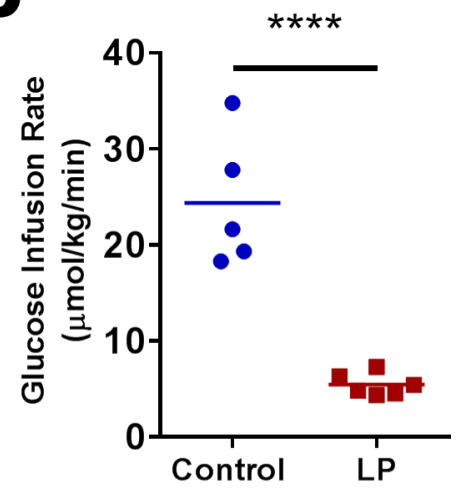

Figure 4.

Euglycemic hyperinsulinemic clamp for male and female offspring.

Figure showing the clamped blood glucose concentrations along with the respective glucose infusion rates to maintain homeostasis for male (A and B) and female (C and D) LP programmed offspring in comparison with their respective controls. **p<0.01, $* * * * \mathrm{p}<0.0001,(\mathrm{n}=5-6)$. 


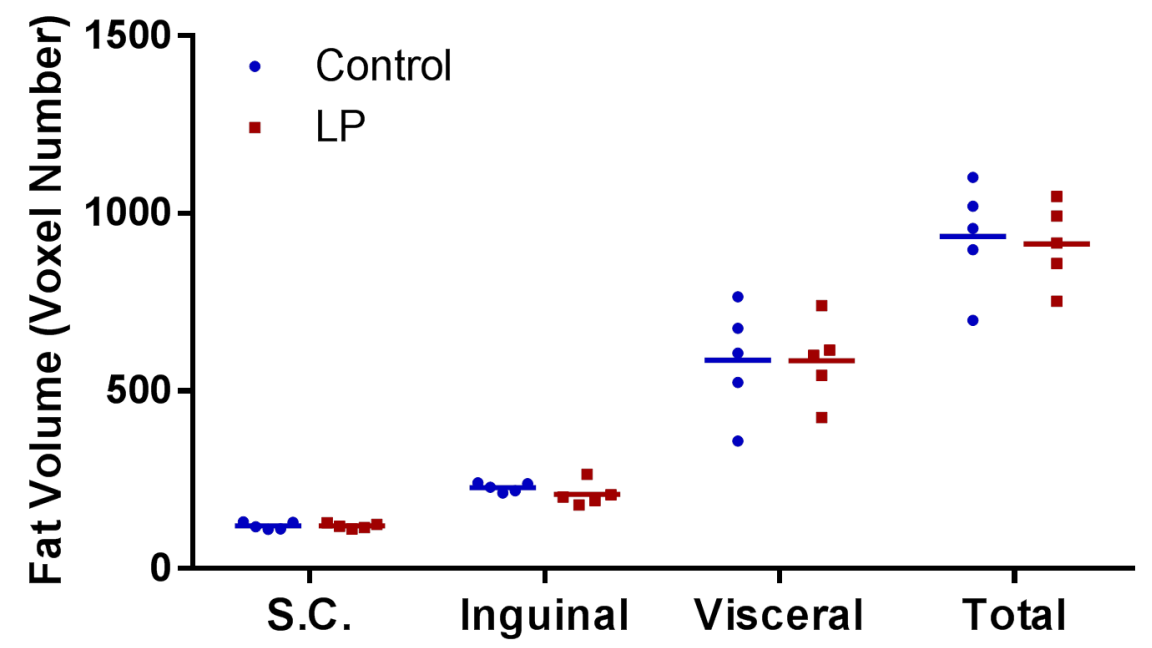

Figure 5.

Magnetic resonance imaging of body fat in female offspring.

MRI analysis showing no changes in sub-cutaneous (S.C), inguinal, visceral and total fat content of control and LP offspring in 4 month old females. $(n=5)$. 


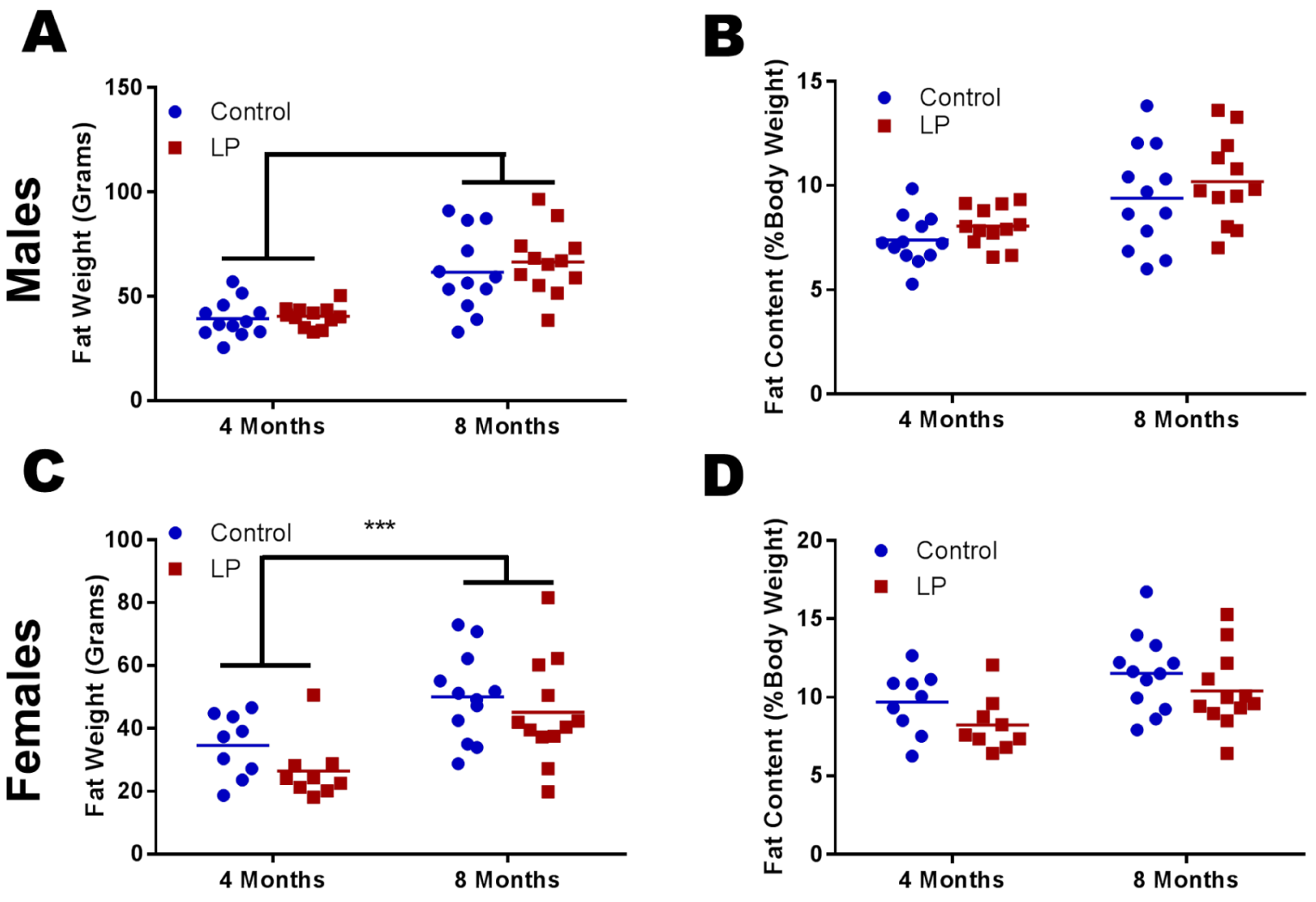

Figure 6.

Weights of fat pads from 4 and 8 months old male and female offspring.

Figure showing the weights and $\%$ body weights of fat pads collected from 4 and 8 month old males (A and B) and females (C and D) LP programmed offspring along with their respective controls. $* * * \mathrm{p}<0.001, * * * * \mathrm{p}<0.0001,(\mathrm{n}=10-12)$. 